Supplement of Atmos. Chem. Phys., 18, 5931-5951, 2018

https://doi.org/10.5194/acp-18-5931-2018-supplement

(C) Author(s) 2018. This work is distributed under

the Creative Commons Attribution 4.0 License.

(c) (1)

Supplement of

Ship-based MAX-DOAS measurements of tropospheric $\mathrm{NO}_{2}, \mathrm{SO}_{2}$, and HCHO distribution along the Yangtze River

Qianqian Hong et al.

Correspondence to: Ka Lok Chan (ka.chan@dlr.de) and Cheng Liu (chliu81@ustc.edu.cn)

The copyright of individual parts of the supplement might differ from the CC BY 4.0 License. 


\section{Unit conversion}

For the estimation of primary and secondary sources of $\mathrm{HCHO}$, the measured $\mathrm{HCHO}$ used in the regression model is ground mixing ratios. Usually, surface HCHO mixing ratios can be obtained from the HCHO vertical profiles (e.g., 0-200 m layer) (Wang et al., 2014). As the viewing elevation angles of the MAX-DOAS measurements only include $30^{\circ}$ and $90^{\circ}$, therefore, there is not enough information to retrieve HCHO vertical profiles. In this study, we use a simplified formula introduced by (Lee et al., 2008) to convert mean HCHO DSCDs to mixing ratios (ppbv).

$$
M(\mathrm{ppb} v)=1.25 \times \frac{D S C D\left(\text { molecule } \mathrm{cm}^{-2}\right)}{d A M F} \times \frac{1}{2.688 \times 10^{16}\left(\text { molecule } D U^{-1}\right)} \times \frac{1}{\Delta P(\text { atom })}
$$

where $\mathrm{M}$ is the mixing ratio, DSCD is the difference between the SCDs of the measured spectrum and that of the Fraunhofer reference spectrum, dAMF is a differential air mass factor $\left(\mathrm{dAMF}=\operatorname{AMF}\left(\alpha=30^{\circ}\right)-\operatorname{AMF}\left(\alpha=90^{\circ}\right)\right)$, and $\Delta \mathrm{P}$ is the pressure difference between surface and $500 \mathrm{~m}$ height of boundary layer. The AMFs for this study were calculated using the radiative transfer model SCIATRAN 2.2 as described in Section 2.2.4. 
Fig. S1. Illustration of the MAX-DOAS setup location on the measurement ship. The red rectangle indicates the ship's exhaust. The blue rectangle represents the MAX-DOAS instrument, measuring in $90^{\circ}$ azimuthal direction (blue arrow) relative to the ship's heading (black arrow).

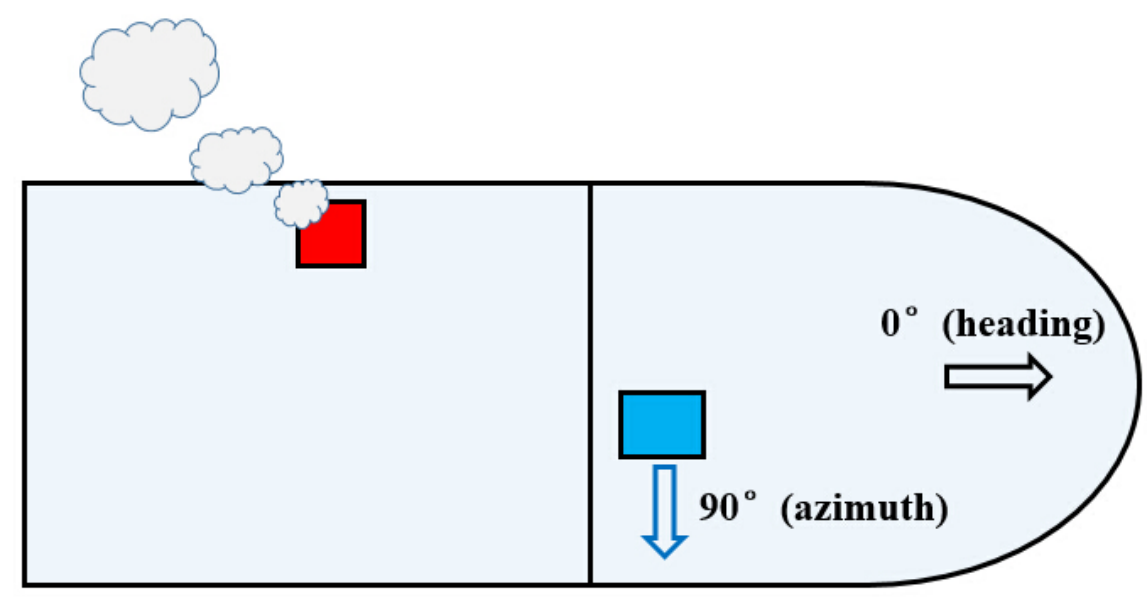


Fig. S2. Sensitivity analysis of the influence of aerosol load on tropospheric (a) $\mathrm{NO}_{2}(354 \mathrm{~nm})$, (b) $\mathrm{SO}_{2}$ (311 nm), and (c) HCHO (347 nm) AMFs. AMFs are calculated using the radiative transfer model SCIATRAN. The tropospheric AMFs deduced under the assumption of different aerosol optical depths (AOD).
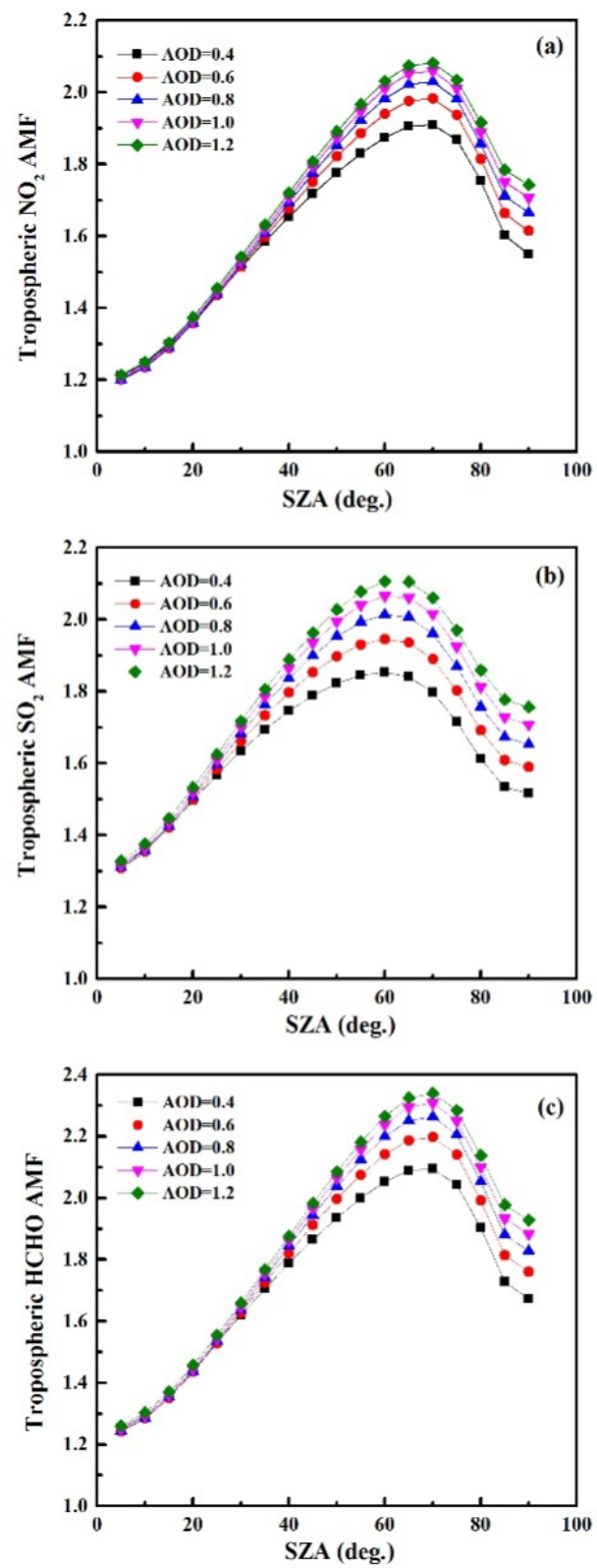
Fig. S3. An example of determination of tropospheric $\mathrm{NO}_{2}$ from the spectra measured on 28 November 2015. (a) $\mathrm{NO}_{2}$ DSCDs, (b) $\mathrm{DSCD}_{\text {offset }}$ (see Eq. 10) plotted as a function of time (green points), (c) Tropospheric $\mathrm{NO}_{2}$ AMFs calculated by the radiative transfer model SCIATRAN, (d) The tropospheric VCDs of $\mathrm{NO}_{2}$ calculated by new and standard method (corresponding to Eq. 7 and Eq. 8).
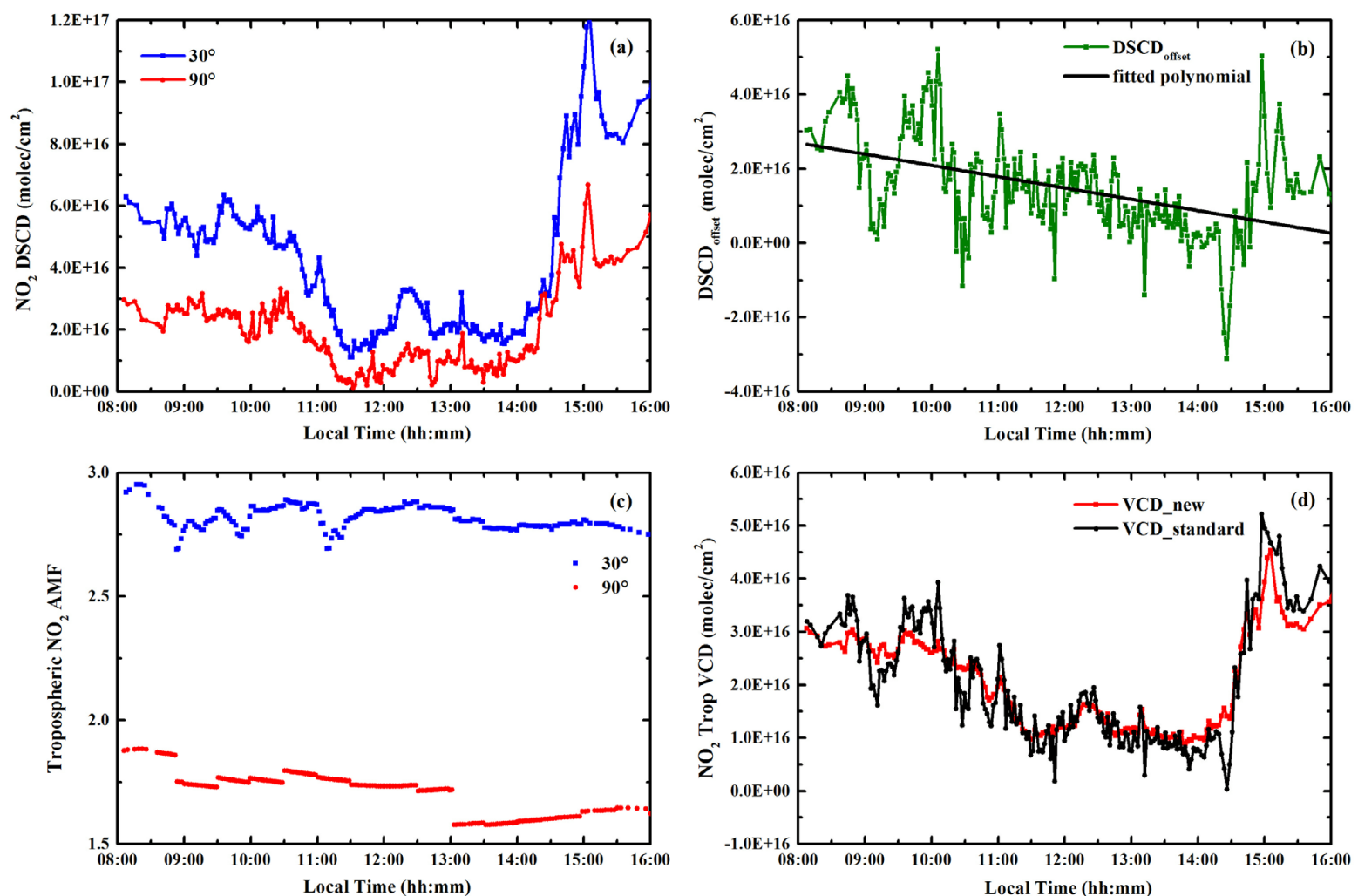
Fig. S4. Same as Fig. S4, but for an example of determination of tropospheric $\mathrm{SO}_{2}$ from the spectra measured on 27 November 2015.
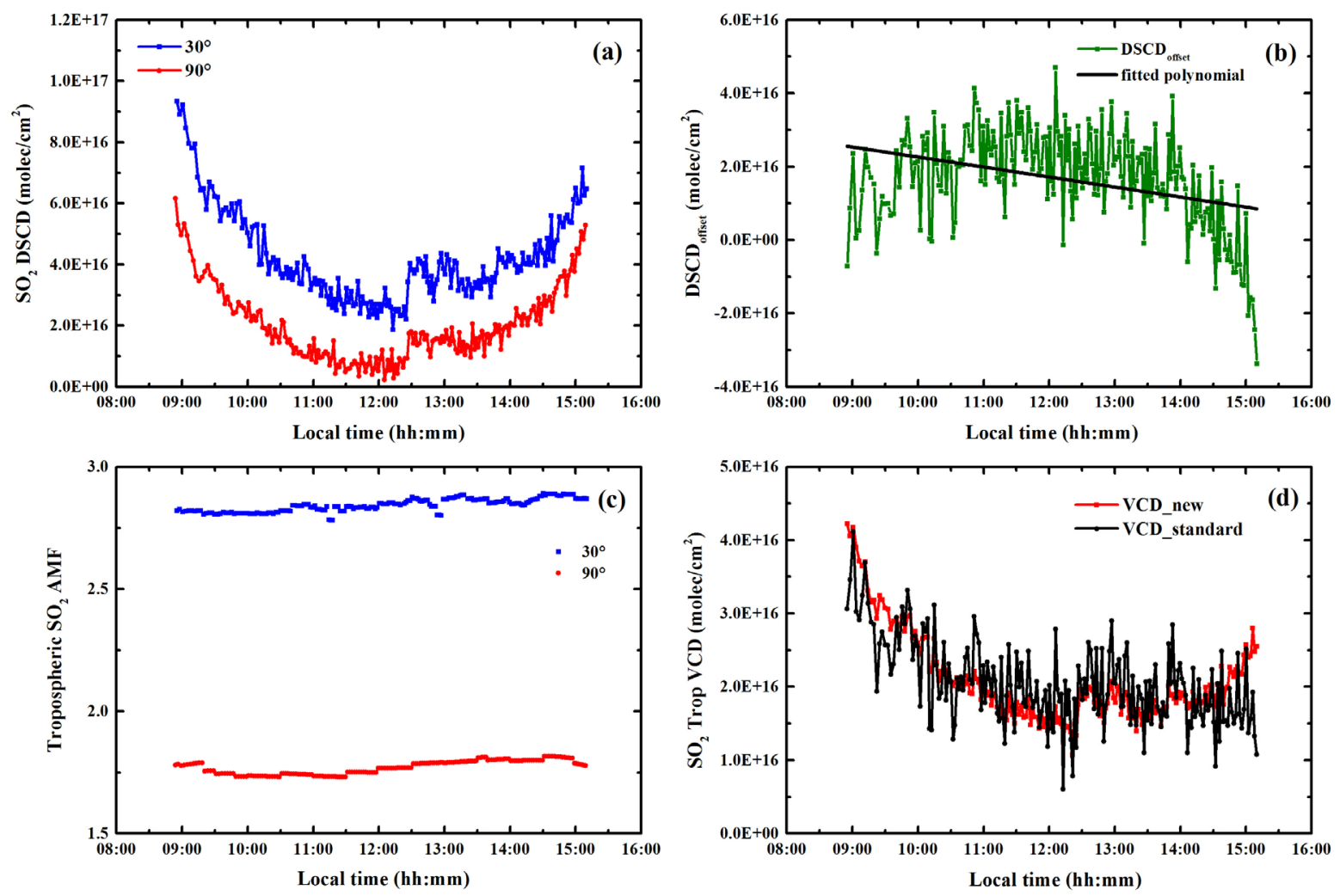
Fig. S5. Same as Fig. S4, but for an example of determination of tropospheric HCHO from the spectra measured on 2 December 2015.
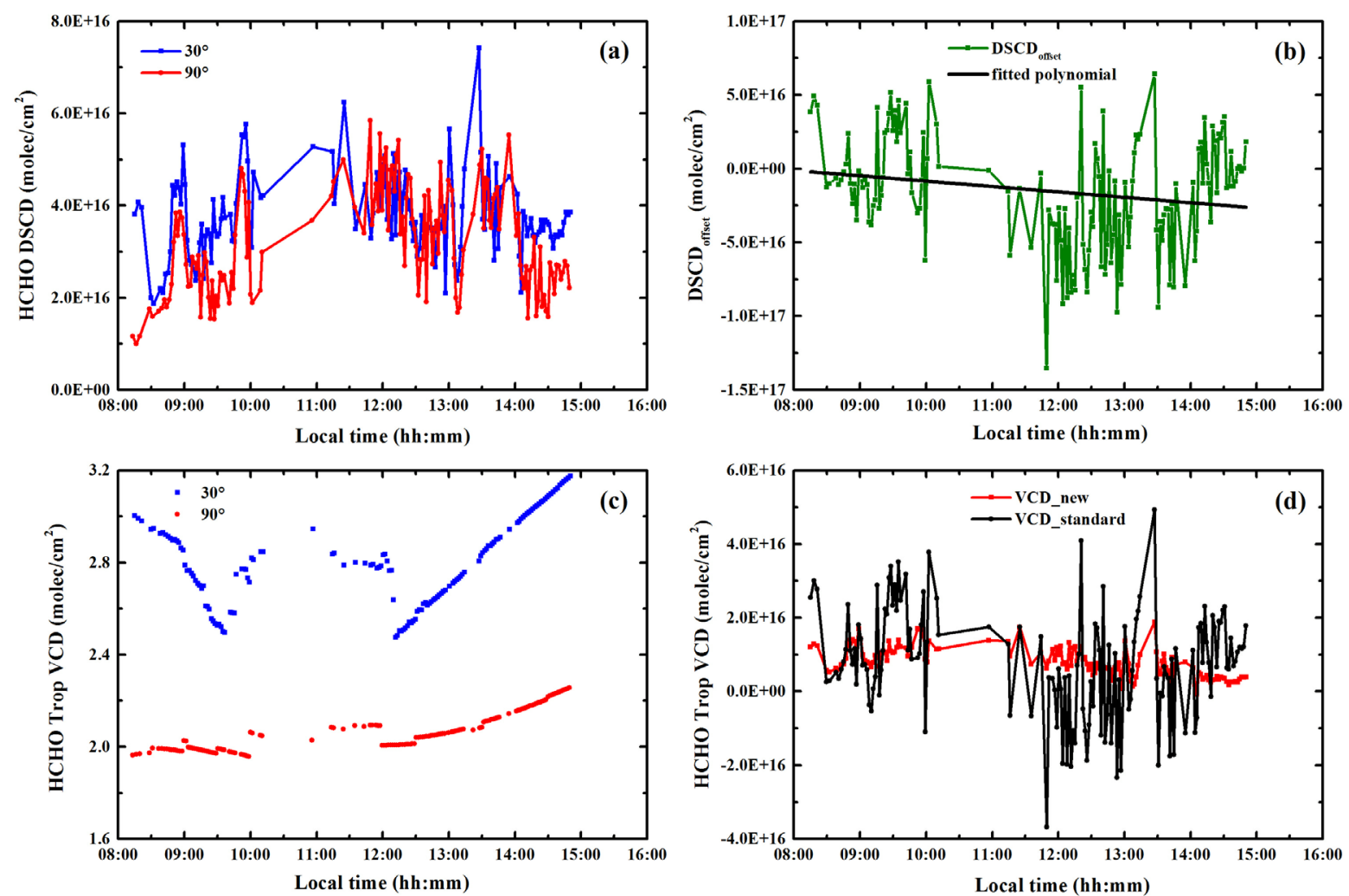
Fig. S6. Frequency distribution of (a) $\mathrm{NO}_{2}$, (b) $\mathrm{SO}_{2}$, and (c) $\mathrm{HCHO}$ VCDs during Yangtze River campaign.
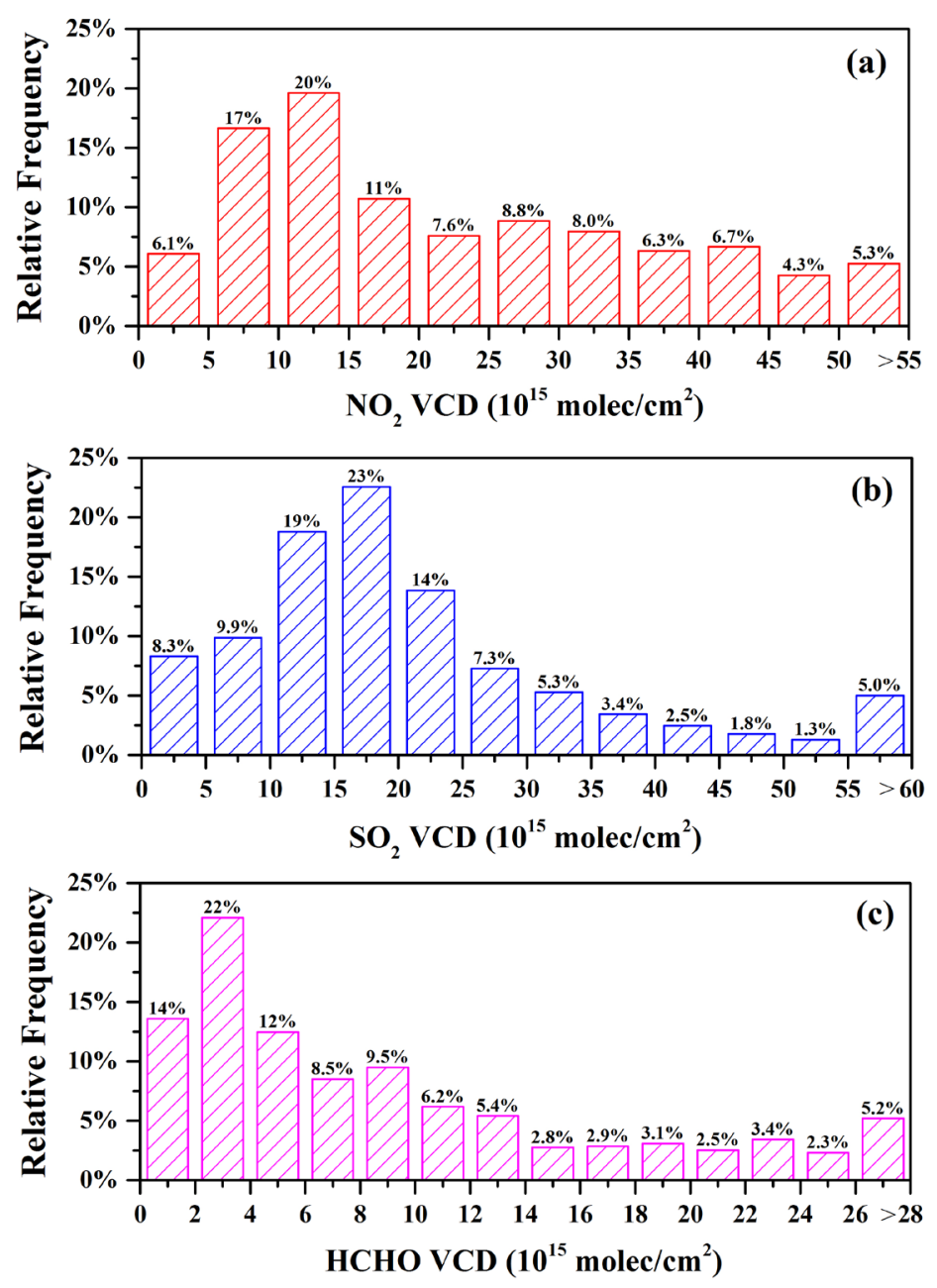


\section{References:}

Lee, C., Richter, A., Lee, H., Kim, Y. J., Burrows, J. P., Lee, Y. G., and Choi, B. C.: Impact of transport of sulfur dioxide from the Asian continent on the air quality over Korea during May 2005, Atmospheric Environment, 42, 1461-1475, 2008.

Wang, T., Hendrick, F., Wang, P., Tang, G., Clémer, K., Yu, H., Fayt, C., Hermans, C., Gielen, C., and Müller, J.-F.: Evaluation of tropospheric $\mathrm{SO}_{2}$ retrieved from MAX-DOAS measurements in Xianghe, China, Atmospheric Chemistry and Physics, 14, 11149-11164, 2014. 